Resumo

$O$ artigo apresenta uma discussão e uma análise, de orientação psicanalitica, do atendimento a bebês por duas professoras do Programa de Educação Precoce oferecido pela Secretaria de Educação do Distrito Federal, em que se pode observar os lugares diferenciados que ambas atribuiam à relação mãebebê na intervenção profissional. Durante e após as observações dos atendimentos, aplicou-se o protocolo IRDI (Indicadores Clinicos de Risco para o Desenvolvimento Infantil). Os resultados da pesquisa apontaram que a profissional que adotava um modelo de intervenção voltado para a criança e seu diagnóstico realizava uma função de maternagem, enquanto a que adotava uma concepção e uma prática voltadas para a relação mãe - bebê mostrou-se capaz de exercer suplência das funções materna e/ ou paterna nos atendimentos. $O$ estudo destaca que a psicanálise pode apresentar-se como um aporte conceitual relevante para os profissionais que atuam no Programa, pois os convoca a uma intervenção focalizada na relação mãe-bebê, em que o profissional não apenas operaria como apoio instrumental-funcional à criança, mas, sim, como suporte às operações constituintes do sujeito. Descritores: estimulação precoce; psicanálise; risco psíquico.

\title{
A RELAÇÃO MÃE-BEBÊ NA EŞTIMULAÇÃO PRECOCE: UM OLHAR PSICANALÍTICO
}

\author{
Amanda Cabral dos Santos Goretti \\ Sandra Francesca Conte de Almeida \\ Viviane Neves Legnani
}

DOl: http://dx.doi.org/10.11606/issn. 1981-1624.v19i3p414-435

\section{Introdução}

$\mathbb{N}$

ão há nenhuma possibilidade de que um recém-nascido sobreviva sem o acolhimento do Outro, mesmo quando se encontra em estado clínico ótimo ao nascimento. Para Freud (1925/1980), a mãe, ao acolher o grito do bebê, o faz por ter o desejo de que o recém-nascido sobreviva, sendo capaz não só de cuidar de suas necessidades orgânicas, como também de fazer um investimento de amor, estabelecendo, assim, o que Lacan (1995) denominou de relação

- Fisioterapeuta e professora de Educação Física. Mestre em Psicologia pela Universidade Católica de Brasília, Brasília, DF, Brasil.

- Psicanalista. Professora dos Programas stricto sensu em Psicologia e Educação da Universidade Católica de Brasília, Brasília, DF, Brasil.

- - Psicanalista, professora da Faculdade de Educação da Universidade de Brasília, Brasília, DF, Brasil. 
primordial. Tendo por base o amor, a função materna implica num conjunto de elementos individuais, históricos, sociais e culturais que captura o bebê no campo do Outro, ou seja, na linguagem. Há uma troca de expectativas, de olhares e desejos entre a mãe e seu bebê, funcionando como uma rede que enlaça o infans e lhe possibilita constituir-se sujeito (Bastos, 2003). Nas palavras de Jardim (2010), “o sujeito psíquico advém de uma operação que vai do corpo à imagem, da imagem à palavra e da palavra ao desejo" (p. 227).

Para Jerusalinsky (2011), o surgimento do sujeito psíquico é possível quando se estabelece na relação mãe-bebê a articulação de quatro operações: o estabelecimento da demanda - que é a correspondência entre as urgências vitais do bebê e a significação da mãe que seja capaz de produzir satisfação ao filho; a suposição de sujeito - quando a mãe supõe que seu bebê é o portador da resolução do enigma sobre seu desejo, isto é, quando a mãe consegue ver no seu bebê a possibilidade de realização daquilo que ela antecipou e, por isso, é capaz de frustrar, atender ou priorizar as demandas que o bebê possa efetivamente dirigir a ela. A alternância - quando a mãe não se coloca como pura ausência ou pura presença nos cuidados exercidos, criando, assim, um ritmo constante de presença-ausência: olhar-não olhar; voz-silêncio; fome-saciedade; sonovigília. E, por fim, a alteridade - quando a mãe não toma o bebê como puro objeto de sua satisfação e não coloca a satisfação acima da lei.

Em outras palavras, por meio dos seus cuidados, a mãe toma seu bebê como alguém que dela depende para se constituir como sujeito com conteúdos psíquicos próprios. Supõe que o choro e os gritos do bebê querem dizer sobre o frio, fome ou dor que esteja sentindo, percebendo e interpretando uma intencionalidade na manifestação da criança. Ela promove, no cotidiano, o estatuto de um sujeito falante antes mesmo que a criança fale (Levin, 1995). Segundo Kupfer (2010b), "esse Outro é propriamente a estrutura da qual a criança pequena deverá extrair a argamassa e os tijolos com os quais construirá a sua subjetividade" (p. 270). A mãe, dessa forma, fornece subsídios para que o seu bebê construa uma base psíquica que norteará as demais aquisições do processo de desenvolvimento (Crespin, 2004; Jerusalinsky, 2002).

Todavia, a relação primordial entre mãe-bebê pode vir a ter impasses quando ocorre alguma intercorrência durante a gestação, parto ou nos primeiros meses de vida do bebê, que implique riscos para o seu desenvolvimento como, por exemplo, nos casos de lesão cerebral pré, peri ou pós-natal, diagnóstico de síndrome genética, parto prematuro ou qualquer alteração fisiológica que demande um período de internação. 
Nessas circunstâncias, o bebê imaginário, construído anteriormente na expectativa e fantasia maternas, é colocado em xeque face à criança real. Assim, o risco subjetivo na relação corresponde, além da doença ou da malformação propriamente ditas, ao fato de que o anúncio do diagnóstico pode vir a tornar impossível o encontro entre a mãe e o bebê. Crespin (2004) pontua que pode haver uma "catástrofe subjetiva", um desinvestimento do bebê real, que pode ser traduzida tanto por um abandono, como por uma superproteção; no último caso, é a deficiência que se encontra investida e não o bebê como sujeito, que se torna objeto de meros cuidados.

No Distrito Federal, as crianças com algum desses tipos de acidente patológico são acolhidas no programa de Educação Precoce da Secretaria de Educação, que visa a promover o desenvolvimento das potencialidades da criança de 0 a 3 anos e 11 meses de idade, no que se refere aos aspectos físicos, cognitivos, psicoafetivos, sociais e culturais. Em suas diretrizes, destaca o processo de interação e comunicação com a criança por meio de atividades lúdicas, assim como a orientação, o apoio e o suporte às famílias (Distrito Federal, 2006, p. 11).

Esse programa está sob a responsabilidade da Diretoria de Ensino Especial (DEE) e recebe crianças com necessidades educacionais especiais decorrentes das denominadas deficiências intelectual, visual, auditiva, física/motora e múltipla, bem como aquelas que têm o diagnóstico de Transtorno Global do Desenvolvimento (TGD). Atende, ainda, crianças prematuras, por serem consideradas de risco, vulneráveis, e apresentar atrasos no seu desenvolvimento global.

Desse modo, a Estimulação Precoce recebe recém-nascidos com as seguintes condições de risco: asfixia perinatal, prematuridade, problemas neurológicos, tamanho incompatível com a idade gestacional, hiperbilirrubinemia, policitemia sintomática, hipoglicemia sintomática, uso de ventilação mecânica, infecções congênitas, malformações congênitas e síndromes genéticas (Brasil, 1995; Brasil, 2000).

Algumas questões relativas ao atendimento às crianças com risco no desenvolvimento, realizado no contexto do Programa, mereceram atenção de nossa parte e orientaram a realização de uma pesquisa de Mestrado, conduzida pela primeira autora (Goretti, 2012), sob a orientação e a supervisão das coautoras, respectivamente. Prevaleceria o ideário de propor às famílias estímulos à criança, visando a amenizar ou sanar seus prováveis ou supostos déficits? Como os profissionais da Educação Precoce concebiam a importância da relação mãe-bebê? Em que medida suas práticas e intervenções incluíam o Outro no tratamento? A intervenção, apesar de considerar os aspectos biopsicossociais do bebê em 
tratamento, privilegiava os aspectos orgânicos em detrimento da relação mãe-bebê, dimensão essencial para o desenvolvimento e constituição subjetiva da criança?

Foram essas indagações que desencadearam a pesquisa realizada com profissionais do Programa de Educação Precoce, cuja discussão e resultados apresentamos, sinteticamente, neste artigo. A referência teórica foi a da psicanálise, que enfatiza que bebês em condição de risco merecem uma cuidadosa atenção, e estudos que apontam que as dificuldades da mãe para construir a relação com o bebê podem inviabilizar a armação de uma estrutura psíquica que possibilite seu desenvolvimento, nos aspectos motores, cognitivos, afetivos e sociais (Crespin, 2004; Jerusalinsky, 2002; Piccinini et al., 2010).

Segundo Legnani e Almeida (2009), a psicanálise recusa o foco no déficit e vai intervir no que o bebê necessita não só para desenvolver-se, mas para constituir-se como sujeito. A intervenção orientada pela psicanálise formula uma primeira pergunta a ser feita ao se iniciar um trabalho com bebês: "Quem é este bebê que ainda não fala, que antes de começar a ser no laço familiar, já pode ter sua estruturação psíquica ameaçada e, portanto, também impedida sua possibilidade de futura integração social?” (Molina, 1998, p. 11). Para Teperman (2005), adotando-se essa perspectiva, é possível auxiliar os pais a lidar com a questão da diferença no bebê, resgatando o desejo obstaculizado pelo diagnóstico e atenuando, desse modo, seus efeitos iatrogênicos na constituição da criança.

\section{O cenário atual de atendimento ao bebê}

\section{Intervenções com foco na relação profissional-bebê}

Faremos aqui um breve resumo dos modelos vigentes de intervenção de atendimento aos bebês, visando a definir melhor o cenário de pesquisa, já que na área encontram-se muitos conceitos divergentes, embora, para o senso comum, sejam considerados idênticos ou muito semelhantes.

\section{Programa de estimulação psicomotora}

Teve início em 1967, em uma creche de Paris, e era voltado para crianças sem alterações aparentes em seu desenvolvimento global. Em 1974, passou a atender também crianças com suspeita de deficiência sensorial. Tem preocupações educativas, preventivas e curativas e é voltado para fisioterapeutas e psicólogos com experiência na primeira infância, embora aceite que mães e cuidadores realizem a técnica, desde que sejam devidamente "treinados". Consiste 
na aplicação de exercícios, pelo profissional, em bebês de quatro a oito meses de idade, visando à estimulação passiva e ativa do sistema de comunicação (gestos, tonicidade, mímica, visão, propriocepção e audição). Considera que o desejo e a ferida narcísica da mãe são relevantes para o desenvolvimento da criança, reportando-se aos trabalhos de Freud, Spitz e Winnicott, mas restringe seu modelo prático de atuação à realização de técnicas e provas padronizadas por profissionais capacitados, denominados “operadores” (Herren, 1986).

\section{Terapia psicomotora}

Criada pelo italiano Mauro Vecchiato, professor de Educação Física e psicólogo, é uma intervenção que utiliza a relação entre o corpo do profissional e da criança para atuar no funcionamento psíquico da mesma. Para isso, defende que os processos mentais têm origem no corpo e nas experiências vividas por meio dele e apoia-se em autores como Piaget, Schilder, Wallon, Erickson, Spitz e Winnicott, mas também cria uma teoria própria, com termos como sensação de difusão, fusão e ritmo, para referir-se ao processo de desenvolvimento psíquico (Vecchiato, 2003). O autor não limita uma faixa etária precisa de atuação, mas considera a terapia voltada para a psicopatologia do nascimento ao pleno amadurecimento físico e psíquico da criança (por volta dos seis anos de idade).

Essa terapia, por meio do jogo psicomotor, estabelece relações corporais de diálogo tônico-emocional para o desenvolvimento de uma personalidade mais integrada da criança.

\section{Intervenção precoce}

Consiste na aplicação de técnicas baseadas na teoria neuromaturacional (Gesell \& Amatruda, 1945) e na teoria ecológica dos sistemas (Bronfenbrenner, 1996). Tem como objetivo estimular o desenvolvimento neuro-sensório-motor de crianças, evitando a formação de padrões anormais de posturas e movimentos. A avaliação dos bebês em atendimento é feita por meio do Inventário Portage 
Operacionalizado - IPO (Willians \& Aiello, 2001), juntamente com a Alberta Infant Motor Scale (Piper \& Darrah, 1994).

Nesse tipo de intervenção, o foco do tratamento está na criança e o papel dos pais é "periférico" (Formiga, 2010, p. 135), ou seja, os pais podem ser usados como co-terapeutas, reproduzindo as técnicas utilizadas, ou podem apenas receber e dar informações a respeito do comportamento da criança. Seguindo a teoria ecológica, Formiga (2010) afirma que, em alguns casos, para que a criança mude determinado comportamento, é necessário mudar o ambiente em que ela vive com os seus familiares.

\section{Intervenções com foco na relação mãe-bebê}

\section{Observação de bebês}

Esse modelo foi introduzido por Esther Bick, em 1949. Consiste na observação da relação mãe-bebê sem que haja intervenção. A presença do observador acaba por monitorar a função materna. Nessa modalidade de atendimento, pode-se identificar o que propôs Winnicott: observar um bebê em uma situação estabelecida, que forneça informações sobre o desenvolvimento emocional do bebê, como, por exemplo, pedir para que a mãe sente-se com seu bebê no colo, de modo que ele possa alcançar uma espátula em cima da mesa, caso queira (Teperman, 2005).

\section{Psicoterapia breve mãe-bebê}

Cramer e Palacio-Espasa apresentam o modelo denominado "técnicas psicoterápicas mãe-bebê", desenvolvido na Universidade de Genebra. O modelo tem como premissa que a mãe estabeleça uma demanda em relação ao filho. O objeto de intervenção é a relação mãe-bebê e, por isso, é estabelecido previamente um período de intervenção. Não é um modelo indicado nos casos de patologias graves na mãe e/ou na criança. Rosine Debray, psicanalista francesa, sugere um modelo de psicoterapia interventiva iniciada pelo pediatra, que precisa atentar-se não 
só para a relação mãe-bebê, mas para as marcas constitutivas da criança. Para Debray, por haver uma decepção recíproca da mãe e do bebê, ela propõe que o terapeuta reanime e fortaleça a relação, protegendo o narcisismo da mãe. Trata-se, portanto, de uma terapia voltada mais para a mãe do que para o bebê (Teperman, 2005).

O Núcleo de Infância e Família da Faculdade de Psicologia da UFRGS desenvolve pesquisas sobre essa modalidade de intervenção, utilizando a abordagem psicodinâmica de Cramer e PalacioEspasa, abordagem familiar-sistêmica e conceitos de Stern, que sustentam a relação mãe-bebê como estruturante da personalidade (Prado, Gomes \& Piccinini, 2009).

\section{Psicanálise com bebês}

Esse tipo de intervenção enfatiza a palavra e a simbolização do sofrimento. Tem como precursora Françoise Dolto e seguidoras como Caroline Eliacheff, que atua com bebês abandonados, Myriam Szejer, que atua em maternidades e Catherine Mathelin, que intervém dentro das Unidades de Terapia Intensiva para Neonatos. A intervenção se dá falando à criança o que perturba a relação entre ela e sua mãe ou entre ela e ela mesma. Mesmo que a criança não fale, o analista opera no campo da linguagem que já existe no bebê. Não está centrada na interação mãe-bebê, mas no bebê como sujeito do desejo. Nesse modelo, o psicanalista atua na demanda dos pais e não em suas necessidades e desejos. Atua muito precocemente, na perspectiva da prevenção (Teperman, 2005).

Atualmente, é referência na clínica psicanalítica com bebês a psicanalista Graciela Crespin (2004), que se dedica aos problemas relacionados ao sofrimento nos primeiros anos de vida de uma criança e seus cuidadores. Ela atua em Centros de Atendimento de Proteção Materno-Infantil (PMI), em Paris, principalmente com crianças autistas, e fundamenta-se nas teorias de Lacan e Winnicott. Separa os sinais de sofrimento do bebê em "barulhentos" e "silenciosos" e defende que, quando detectados, podem ser trabalhados em parceria com os demais especialistas, em benefício do bebê. 
Estimulação precoce orientada pela psicanálise

No Centro Dra. Lydia Coriat, em Buenos Aires e Porto Alegre, esse tipo de intervenção sustenta-se por meio de uma prática interdisciplinar. É uma técnica que apoia a criança no desenvolvimento de suas funções instrumentais. A intervenção terapêutica ocorre quando a espontaneidade do processo de desenvolvimento é interrompida por um acidente patológico. Estimula as funções já existentes no sujeito, proporcionando situações a partir do nível em que se encontram. Por isso, é necessário conhecer a sequência do desenvolvimento, embora não seja uma técnica comportamentalista. $\mathrm{O}$ procedimento consiste em reconstruir, sustentar, ou substituir a função materna, sendo o terapeuta um terceiro na relação mãe-bebê. A escuta psicanalítica permeia todo o tratamento, mas não há intervenções psicoterapêuticas e, por isso, a Estimulação Precoce que segue esse modelo não é uma psicanálise com bebês. Apesar de ser uma clínica interdisciplinar, é adotado um terapeuta único que se responsabiliza pelas intervenções diretas, por entender que até os três anos de idade o desenvolvimento da criança ainda não tem uma diferenciação instrumental. A partir dessa idade, por já haver uma complexificação da organização funcional da criança, ela passa a necessitar de profissionais específicos, de acordo com suas necessidades. A intervenção situa o orgânico como limite e não como causa. Assim, não é o diagnóstico que diferencia essa prática das demais práticas de Estimulação Precoce. Quem conduzirá o tratamento será o profissional de transferência com os pais, já que nesse modelo de clínica interdisciplinar não existe hierarquia.

\section{Educação terapêutica}

O termo, cunhado por Maria Cristina Kupfer, e adotado na Associação Lugar de Vida, em São Paulo, compõe um conjunto de práticas interdisciplinares de tratamento, com ênfase nas práticas educacionais, que visa tanto à retomada do desenvolvimento global da criança quanto à retomada da estruturação do sujeito do inconsciente, e à sustentação do mínimo de sujeito que uma criança possa ter construído (Kupfer, 2010a).

Essa modalidade de intervenção começou a ser desenvolvida em 1990, como um serviço oferecido pelo Departamento de Psicologia da Aprendizagem, do Desenvolvimento e da Personalidade, do Instituto de Psicologia da Universidade de São Paulo - PSA/IPUSP. Inicialmente, era voltada para o atendimento educacional e terapêutico de crianças autistas e 
psicóticas. Em 1995, a instituição passou a se chamar Pré-escola Terapêutica Lugar de Vida e, hoje, é denominada Associação Lugar de Vida - Centro de Educação Terapêutica.

$\mathrm{Na}$ perspectiva da educação terapêutica, a intervenção com bebês faz-se necessária não só na presença dos pais reais, mas também prestando-se atenção ao discurso imaginário, alimentado pela cultura, que se apresenta sobretudo nas creches e nas escolas, atravessado por crenças pessoais, representações sociais e fantasias acerca dos bebês e crianças com transtornos graves de desenvolvimento. Assim, a intervenção focaliza a relação mãe-bebê e o estabelecimento da cadeia de significantes que está armando e constituindo a estrutura do sujeito, no meio familiar, social e escolar.

\section{Os caminhos do estudo}

Após a exposição do panorama atual dos atendimentos às crianças de 0 a 4 anos, podemos precisar melhor o objetivo deste estudo: investigar o lugar atribuído à relação mãe-bebê nas práticas de profissionais da área da Educação Precoce, na rede pública de ensino do Distrito Federal.

As crianças observadas foram escolhidas pelas próprias professoras que atuavam na Estimulação Precoce e tinham a idade entre zero e 18 meses de idade. A escolha dessa faixa etária se deu pelo fato de o protocolo "Indicadores Clínicos de Risco para o Desenvolvimento Infantil” (IRDI), instrumento utilizado como referência nesta pesquisa, ter sido validado para a avaliação de crianças nessa faixa etária (Lerner \& Kupfer, 2008).

O protocolo IRDI foi desenvolvido como resultado de uma pesquisa realizada no período de 2000 a 2008, em 11 serviços de saúde de nove cidades brasileiras. Tendo como referência a teoria psicanalítica, 31 indicadores foram construídos e aplicados em 726 crianças entre zero e 18 meses de idade. Uma sub-amostra, com a idade de três anos, foi reavaliada. Os resultados estatísticos e qualitativos apontaram a capacidade de o protocolo IRDI predizer problemas de desenvolvimento e destacaram, ainda, 15 indicadores com 
capacidade preditiva de risco psíquico para a constituição subjetiva. Como se trata, no Brasil, do único modelo de acompanhamento do desenvolvimento infantil que privilegia, sem desconsiderar os aspectos maturacionais, a articulação entre desenvolvimento e sujeito psíquico (Kupfer et al., 2010), foi utilizado como base da construção das observações e da análise das informações colhidas junto às professoras, na pesquisa por nós conduzida.

Os indicadores estão estruturados basicamente em quatro eixos, que compõem as quatro operações psíquicas constituintes do sujeito, e que podem ser observadas nas situações cotidianas entre mãe-bebê:

EIXO 1 - suposição de sujeito (SS): considerada a antecipação realizada pela mãe ou cuidador que gera prazer ao bebê e vem acompanhada de uma manifestaçáo de júbilo da mãe como, por exemplo, palavras pronunciadas com uma musicalidade prazerosa, chamada de mamanhês ou manhês.

EIXO 2 - estabelecimento de demanda (ED): ação do bebê reconhecida pela mãe ou cuidador como um pedido. Exemplo: atribuir uma significação distinta à fome, sono ou dor quando o bebê chora.

EIXO 3 - alternância presença-ausência (PA): açóes maternas que a tornam alternadamente presente e ausente para a criança. Postergar o horário da oferta do seio, por exemplo, mas fornecê-lo de forma a aplacar o mal-estar do bebê, ocasionado pela tensáo face à fome.

EIXO 4 - função paterna (FP): baliza a função materna e pode ser chamada também de alteridade, isto é, ações cotidianas que denotam a presença de um terceiro na relação entre mãe-bebê (Kupfer et al., 2009; Kupfer et al., 2010; Lerner \& Kupfer, 2008).

Os 31 indicadores foram construídos a partir desses quatro eixos e deram origem ao protocolo IRDI, que na pesquisa original foi aplicado à observação da relação mãe-bebê por pediatras treinados para esse fim. Os indicadores, no protocolo, são marcados como presentes, ausentes ou não verificados, mas é a sua ausência que sugerirá risco para o desenvolvimento da criança avaliada. Quando presentes, os IRDIS indicam que o desenvolvimento está acontecendo de forma satisfatória (Kupfer et al., 2009).

No nosso estudo, foram observados quatro atendimentos de bebês, realizados por duas professoras, cujas intervenções apresentavam características bastante diferenciadas: uma que adotava um modelo com foco na criança e no seu diagnóstico, que nomearemos de Bethânia; outra, cuja atuação era voltada para a relação mãe-bebê, que será, aqui, chamada de Vanessa. Neste artigo, faremos o relato de um atendimento de cada professora. 


\section{Os atendimentos \\ observados em Educação \\ precoce: alguns recortes}

\section{Bethânia e o bebê Alberto}

Essa professora era responsável por atender bebês de zero a nove meses de idade. Era formada em Pedagogia, possuía Mestrado em Psicologia e vários cursos de formação na área de Estimulação Precoce.

Alberto, o bebê, era primeiro filho, sua mãe estava com 32 anos de idade. A gravidez não foi planejada, mas desejada. A mãe relatou ter hipertensão arterial e diagnóstico médico de Transtorno Bipolar, tendo feito acompanhamento com psiquiatra. Mas, à época, segundo informações dadas pela professora Bethânia, havia cessado por conta própria a medicação prescrita.

Devido a um pico de pressão arterial, a mãe foi internada quando estava com 38 semanas de gestação e submetida a um parto cesáreo. Alberto nasceu com $2720 \mathrm{~g}, 45 \mathrm{~cm}$, Apgar 8-9. Apresentou desconforto respiratório ao nascer e, na avaliação cardiológica, houve suspeita de Síndrome de Down, que foi posteriormente confirmada. O bebê não foi amamentado no peito e dormia no quarto da mãe. O pai residia em outra cidade e, segundo a mãe, não a ajudava financeiramente nas despesas com o filho. 
Alberto entrou no Programa aos quatro meses de idade e, desde aquele momento, havia sido atendido apenas pela professora Bethânia. Segundo avaliação dos profissionais da instituição, ele apresentava atraso global do desenvolvimento. Quando ocorreu a observação e construção dos dados, Alberto tinha seis meses de idade.

Em ambos os atendimentos observados, a mãe entregou o filho para a professora, mesmo sem ser solicitada, e sentou-se em uma cadeira. Logo em seguida, a professora iniciou a intervenção com estímulos motores, sempre conversando com a criança (manhês) e orientando a mãe sobre vacinas, alimentação e outros cuidados. A professora mostrava-se muito segura e utilizava técnicas bastante eficientes para estimular a criança no seu desenvolvimento motor. Durante as sessões, a mãe se colocava de lado, aparecendo muito pouco na cena e não atuando junto ao filho ao longo do atendimento. Ela se limitava a observar a intervenção da professora e, vez por outra, fazia algumas perguntas, sobre vacinas e alimentação, sobretudo, e tecendo um ou outro comentário sobre a melhora de Alberto.

A mãe, em vários momentos, falou espontaneamente sobre o pai da criança: "Alberto tem a sobrancelha do pai", "ele ligou para saber do filho", "O nome da criança foi escolhido por ele". Após o atendimento, em conversa particular com a pesquisadora, a professora relatou sua preocupação com o desenvolvimento da criança, devido ao fato de "o pai ter abandonado a família".

Para Legnani e Almeida (2009), "sob a ótica da Psicanálise, sabemos que a existência de um pai na realidade não se constitui como garantia na constituição de um sujeito e a clínica que opera com essa convicção situa-se distante da psicanalítica” (p. 27). Nessa direção, pode-se perceber, no caso de Alberto, que mesmo o pai real não estando presente, simbolicamente atravessava o discurso da mãe, o que permitiu inferir que as funções materna e paterna pareciam ter sido operantes. A criança, inclusive, apresentou indicadores, segundo a aplicação do protocolo IRDI, de que estava inscrita no universo simbólico.

Contudo, parecia comparecer, no discurso da profissional que atendia Alberto, um atravessamento na sua posição subjetiva, que atribuía aos diagnósticos da criança e da mãe e ao histórico de "abandono" pelo pai um peso muito significativo cujas dimensões imaginárias podem ter sido incorporadas pela instituição educacional, o que justificaria o modelo adotado pela profissional no atendimento, focalizado nas funções deficientes do bebê.

A assimilação do discurso médico-organicista, no atendimento em Estimulação Precoce, cujas intervenções passam a ter como finalidade o treinamento de determinadas funções e habilidades, corria o risco de 
engessar como "déficits" as dificuldades de desenvolvimento de Alberto, em detrimento de sua individuação singular como sujeito.

\section{Vanessa e o bebê Carolina}

A professora Vanessa atendia bebês de seis meses a quatro anos de idade. Era formada em Educação Física, tinha vários cursos de especialização na área educacional e concluiu o Mestrado em Psicologia sobre o tema interação mãe-bebê.

Carolina, o bebê em atendimento por Vanessa, era a terceira filha, nascida com 37 semanas, de parto cesáreo, com Apgar 5-8 e 2835g. A mãe foi informada, logo após o nascimento, sobre o diagnóstico de Síndrome de Down. Carolina não apresentara nenhuma intercorrência clínica até a época da realização da pesquisa: exames cardiológicos, oftalmológicos e auditivos sem alterações. Ela entrou no programa de Educação Precoce aos três meses de idade. No período da observação, estava com 11 meses e 13 dias. Segundo a avaliação realizada pelos profissionais do Programa, a criança apresentava atraso global do desenvolvimento.

No primeiro atendimento observado, Carolina estava acompanhada da mãe e do pai, que a colocou deitada no colchonete. A professora pediu que ele também se sentasse confortavelmente junto à filha. A mãe ficou sentada em um sofá, sem participar diretamente da cena, pois disse estar com dor nas costas. A proposta da professora, naquele dia, para aproveitar a presença do pai, foi a de que ele fizesse uma massagem em Carolina. Ao lado dos dois, a profissional pediu ao pai que conversasse com a filha, explicando-lhe, também, como fazer a massagem. O pai, muito tímido, com a voz baixa, porém melodiosa, falou: "O papai vai fazer uma massagem em você, você quer?”. A professora Vanessa lhe pediu, então, que aconchegasse a criança sobre seus membros inferiores, enquanto ligava o aparelho de som e colocava músicas instrumentais para tocar. E foi assim que ela começou a orientar o pai a executar os movimentos da shantala, uma massagem de origem oriental específica para bebês.

Ao mesmo tempo em que acompanhava, atentamente, a massagem realizada pelo pai,em Carolina, Vanessa se dirigia a ele, despertandolhe a sensibilidade nos cuidados com a filha: "Você não tá fazendo sopa, você está com sua filhinha no colo. É importante, com seu toque, que você perceba as reações dela." Ao final da massagem, o pai olhou para a filha, com um sorriso no rosto, e disse: "Acho que ela gostou. Agora vou dormir, né, pai?"

No segundo atendimento, Carolina foi acompanhada apenas pelo pai, pois a mãe estava trabalhando. Ele a colocou no colchonete e sentou-se na cadeira. A professora 
lhe perguntou sobre as atividades que a criança frequentava, sendo informada sobre os atendimentos fisioterápicos e psicológicos realizados em uma clínica-escola. O pai apontou: "Lá, a família não pode entrar". Vanessa, então, o indagou sobre aquela conduta e ele opinou: "Ah, prefiro aqui porque aprendo muito.".

Na sequência, ela lhe explicou a importância da participação dos pais no atendimento: "O desenvolvimento de Carolina depende de como ela se relaciona com as pessoas, principalmente com os pais. Por isso, é importante que vocês estejam próximos e que a conheçam”. Aproveitando a oportunidade, a professora perguntou: "Qual a fase em que a Carolina está? O que você acha que precisamos trabalhar com ela?". Como resposta, obteve: "Acho que é o arrastar, porque em casa ela só se desloca rolando".

Em seguida, a profissional colocou a criança deitada no tatame e lhe ofereceu um brinquedo, mas sem o entregar, perguntando ao pai o porquê de estar agindo assim, ao que ele respondeu: "É para ela sair da posição de ficar deitada, né?”. A professora explicou-lhe, então, que a criança precisava de algo que a interessasse para que saísse de uma posição e fosse para outra, pontuando a importância do movimento no fortalecimento da musculatura e no surgimento de novas formas de deslocamento.

A professora ainda acrescentou: "Em casa, brinque com ela, curta a delícia de ter uma filha, de estar disponível." Enquanto os dois brincavam, Vanessa afastou-se e apenas os observava. "É bom que você se sinta confortável para brincar, para que ela também se sinta confortável, acolhida"; "Você pode ir dobrando os joelhos e, assim, ela vai ficando em diferentes posições, tendo que se readaptar."

Na observação dos atendimentos da professora Vanessa, foram avaliados todos os indicadores que constam no protocolo IRDI, já que durante toda a intervenção a mãe e, principalmente, o pai da criança não só estavam na sala como constantemente interagiam com a filha. Houve, ao longo das intervenções, uma postura de valorização da importância das interações pais-bebê por parte da profissional. "Olha para sua filha! Conversa com ela! Fala o que você vai fazer, não fica só chamando"; "Viu que ela olhou pra você? Olha como te chama, pelo olhar"; "Coloca o brinquedo perto, mas não dá na mão, coloca e espera”.

$\mathrm{Na}$ sua prática, a professora motivava os pais a falar com o bebê e os convocava, continuamente, a assumir uma posição (inter)subjetiva na relação, supondo em Carolina um sujeito com algo a dizer. 


\section{Alguns apontamentos sobre os atendimentos observados}

Analisando conjuntamente os indicadores obtidos na observação dos atendimentos das professoras Bethânia e Vanessa, consideramos que o modelo de intervenção adotado pela primeira professora está focado nas deficiências da criança, atribuídas e destacadas pelo diagnóstico. Há um desempenho plástico, ortopédico, das atividades desenvolvidas pela profissional. É ela quem acalma o bebê, quem dá um sentido às suas reações, que fala com ele o mamanhês, mas de uma posição essencialmente técnica, não implicada subjetivamene te. Trata-se, neste caso, do exercício de funções de maternagem (atividades de atenção e de cuidados primários com o bebê) e não do exercício de uma suplência da função materna propriamente dita.

Face às características do atendimento da professora Bethânia, surge uma questão: a função de maternagem, que a professora realiza ao longo de 45 minutos de atendimento, seria suficiente para pôr em andamento ou sustentar as operações constituintes do sujeito? Conforme apontado por Bernardino, Vaz, Vaz e Quadros (2008), somente a partir de uma implicação desejante a professora poderia sustentar, minimamente, a função materna, isto é, exercer uma suplência dessa função.
É o que faz a professora Vanessa, cujas concepções e práticas acerca da Estimulação Precoce se aliam a uma implicação subjetiva desejante, que visa, também, a provocar nos pais uma posição de acolhimento em relação à filha e de suposição de sujeito no bebê. Dito de outro modo, a profissional intervém levando em conta o diagnóstico da criança e suas necessidades, mas mantendo-o em suspensão, ao mesmo tempo em que se dirige a ela reconhecendo-a como sujeito e não objeto de suas intervenções. O lugar que Vanessa ocupa no atendimento demarca sua implicação e instaura a possibilidade de identificação dos pais com a sua posição desejante em relação à criança.

Ao considerar que nem todo estímulo produz marca e nem toda marca resulta num traço atrelado a um funcionamento significante, Jerusalinsky (2011) afirma que uma criança pode até andar, caso seja submetida a estímulos, mas quando inscrita no processo de filiação tornase capaz não só de caminhar, mas de saber para onde está andando, ou seja, será capaz de escolher seu próprio caminho. Para a autora, a inscrição do bebê no universo simbólico se produz não pela força do estímulo percebido de modo aleatório, vindo do meio, mas, sim, por certos traços fundamentais da tela significante do Outro endereçados ao bebê.

Em síntese, não se trata de substituir a função materna, mas de atuar refletindo, como um espelho, as 
funções a serem desempenhadas por mães, pais, avós e cuidadores, de modo a sustentar ou fazer suplência ora da função materna, ora da função paterna. Tal posição não implica no abandono dos aspectos orgânicos e instrumentais necessários ao desenvolvimento da criança, mas significa integrá-los a um atendimento que visa ao sujeito e à sua relação com o Outro. Como lembra Jerusalinsky (2002), um estímulo só é constitutivo de aprendizagem, só faz sentido, se for tomado a partir de uma rede simbólica sustentada pelo Outro encarnado, que, por sua vez, no atendimento, apoia-se na transferência ao profissional.

Na prática que visa ao desenvolvimento e à constituição psíquica do bebê, a autora enfatiza a importância de garantir e testemunhar as produções da criança para que os pais possam operar o reconhecimento de suas diferentes produções. Assim, podem construir suas próprias estratégias de sustentação, manipulação e oferecimento de objetos ao bebê sem que fiquem engessados a modelos impostos pela técnica. Também é essencial que se tornem aptos para realizar leituras das produções tônico-posturais, gestuais, sonoras e de esquemas cognitivos do filho, não só por meio dos conhecimentos técnicos específicos, mas sustentando a singularidade dessas produções, como enigmas de um sujeito em constituição (Jerusalinsky, 2002).

\section{Concluindo}

Atualmente, no Brasil, o número de profissionais que se encarrega da promoção do desenvolvimento de crianças de zero a quatro anos de idade aumentou consideravelmente. Contudo, grande parte dos atendimentos aos bebês com alguma vulnerabilidade e riscos no desenvolvimento ainda segue modelos que visam, sobretudo, a uma funcionalidade, à utilidade e à adaptação da criança ao meio social, por isso mesmo focando as intervenções nas funções motoras, fonológicas, fisiológicas, pedagógicas e psicológicas da criança, de forma fragmentária. 
Cada uma dessas áreas emerge das teorias mais diversas e os profissionais tentam imprimi-las em suas práticas, supondo levar em conta as especificidades do desenvolvimento infantil. No entanto, as dimensões psíquicas do bebê e de seus cuidadores nem sempre estão presentes ou não são consideradas relevantes as operações psíquicas fundantes da constituição do sujeito, nas teorias que servem de referência às práticas profissionais.

Face ao mosaico conceitual e prático dos diversos modelos de intervenção em Estimulação Precoce, o que se destaca é uma valorização das respostas motoras e sensoriais, já que elas que garantiriam, supostamente, as condições de independência da criança. Isso não se dá sem consequências, pois ao longo da pesquisa, observando e conversando com os profissionais dos Centros de Educação Precoce, percebemos claramente a dificuldade que eles têm de pensar e traduzir teoricamente suas práticas e a ênfase dada aos aspectos funcionais do desenvolvimento infantil. Tratase, aqui, essencialmente, de questão ligada tanto à formação inicial quanto continuada dos professores que atuam no Programa de Educação Precoce.

Almeida (2011) defende que "a formação de professores não pode estar centrada apenas nos aspectos didáticos, instrumentais e racionais ligados ao saber-fazer profissional"' (p. 27). Para a autora, trata-se de adotar uma perspectiva ética e não somente técnica no processo de formação. Ela propõe 
lançar mão de dispositivos clínicos para analisar as práticas profissionais articulando as dimensões profissionais, pessoais, subjetivas e interpessoais de cada participante. A aposta é que "o professor possa transformar, mudar e aperfeiçoar suas práticas educativas, engajando-se e implicando-se como sujeito e autor de suas escolhas e ações" (p. 33).

Nessa perspectiva, a formação continuada dos profissionais da Educação Precoce certamente merece maior atenção, na direção de estudos, pesquisas e ações formativas focados no seu desenvolvimento pessoal e aperfeiçoamento profissional, pois a formação docente constitui uma das dimensões que influenciam diretamente as práticas educativas, cuja orientação pode ou não levar em conta a criança-sujeito.

No que diz respeito à relação mãe-bebê, que abriga a função materna, vale enfatizar que ela é uma operação inconsciente e não se dá por meio de um saber instintivo, tampouco técnico-científico. A relação mãe-bebê se estabelece entre o cenário fantasmático de uma mulher, que pode acolher ou descartar inconscientemente o recém-nascido. Com esse entendimento, destacamos a importância da psicanálise como corpo teórico e clínica do sujeito, que aponta que a constituição do sujeito e o desenvolvimento infantil estão atravessados e são afetados pela relação subjetiva e fantasmática mãe-bebê. Tomando essa orientação como referência, as intervenções destinadas aos bebês e às crianças precisam levar em consideração essa relação e, ainda mais, deslocá-la para o centro do atendimento, manejando-a como dispositivo clínico e função a ser observada e trabalhada.

A realização da pesquisa permitiunos observar, também, o quanto o discurso médico sustenta a estrutura do Programa de Educação Precoce, como também as concepções e práticas de seus profissionais. $\mathrm{O}$ avanço das tecnologias diagnósticas e o suposto saber, onipotente, atribuído ao discurso médico, acabam por eximir o sistema educacional e desresponsabilizar as famílias que lidam diretamente com o desenvolvimento da criança. Disso resulta ainda, como consequência, a falta ou o pouco compromisso dos professores com a análise e discussão político-pedagóe gica das condições histórico-sociais e materiais de produção e manutenção de modelos de intervenção que desconsideram a subjetividade do profissional, dos pais e da criança no atendimento. Do mesmo modo, como efeito do lado das famílias, observa-se sua dificuldade em responsabilizarse pelo destino do filho, quando se submetem ao rigor do diagnóstico e ao poder do discurso médico. Quanto maior o poder atribuído a esses dispositivos discursivos, menor o grau de empoderamento da família e de responsabilização subjetiva dos pais.

A aposta que fazemos, ao defender a relação mãe-bebê como 
foco da intervenção, assenta-se na compreensão de que a armação e a sustentação desse dispositivo clínico permitem que o profissional dê suporte instrumental e funcional ao deł senvolvimento da criança, mas também o suporte necessário às operações constituintes do sujeito. $\mathrm{Na}$ articulação entre $\mathrm{O}$ sujeito que se constitui e o corpo que se desenvolve, propomos um reordenamento de concepções e práticas em Estimulação Precoce, no atendimento realizado pela rede pública de ensino, no Distrito Federal. Defendemos, também, uma nova modalidade de formação continuada, na perspectiva da escuta e análise das práticas profissionais (Blanchard-Laville, 2007; Almeida, 2011). Além disso, apoiando-se na concepção psicanalítica de sujeito e lançando mão da aplicação do protocolo IRDI, o Programa de Educação Precoce do DF, por ser um espaço que se ocupa da primeira infância, poderia vir a utilizar esses indicadores clínicos para detectar e encaminhar, a tempo, as crianças em situação de risco psíquico para uma educação terapêutica ou para a estimulação precoce.

Finalmente, entendemos que ao propor uma intervenção orientada pela concepção psicanalítica da constituição do sujeito e uma prática centrada na relação mãe-bebê, visamos mais do que oferecer as condições para uma criança falar e andar. Pretendemos que ela possa "se dizer" e "ir além" das suas supostas deficiências, como sujeito de linguagem e de desejo.

\begin{abstract}
MOTHER-BABY RELATIONSHIP IN EARLY STIMULATION: A PSYCHOANALYTIC VIEW

The article proposes a psychoanalytic discussion and analysis about baby attendance by two teachers of Early Stimulation Program, offered by the Education Department in the Federal District - Brazil. The fulfillment was that these teachers put the mother-baby relationship in particular places in each professional intervention. During and after the attendance fulfillments, IRDI protocol (Clinical Risk Indicators in Child Development) was applied. The results indicate that the professional who adopts models of intervention for children and their diagnosis performance an fulfillment of the infant-care practices, while the professional who adopts a concept and practice focused on mother-baby relationship is able to exercise the maternal and/ or paternal functions in attendance. The research emphasizes that the Psychoanalysis can be an important conceptual support to the professionals of Early Stimulation, because it validates the intervention focused on mother-baby relationship, in which the professional is an instrumental-functional support to the children, but also supports the operations of the constitution of the subject.
\end{abstract}

Index terms: early stimulation; psychoanalysis; psychic risk. 


\section{RESUMEN}

LARELACIÓN MADRE-HIJO EN LA ESTIMULACIÓN TEMPRANA: UNA MIRADA PSICOANALÍTICA

El artículo presenta una discusión y un análisis, de orientación psicoanalitica, del atendimiento a los bebés por dos profesoras del Programa de Educación Precoz ofrecido por la Secretaria de Educación del Districto Federal, en los cuales se puede observar los diferentes lugares que las dos profesoras atribuian a la relación madre-bebé en la intervención profesional. Mientras y después de las observaciones de los atendimientos, se aplicó el protocolo IRDI (Indicadores Clínicos de Risco para o Desarrollo Infantil). Los resultados de la pesquisa mostraron que la profesional que adopta un modelo de intervención dedicado al bebé y su diagnóstico ejecuta una función maternal, en cambio la que adopta una concepción y una práctica dedicadas a la relación madre-bebé se mostró apta para sustituir las funciones materna y paterna en los atendimientos. El estudio señala que la psicoanálisis puede presentarse como una contribución conceptualista importante para los profesionales que actúan en el Programa, pues los convoca a una intervención enfocada en la relación madre-bebé en que el profesional no sólo intervendría como un soporte instrumental-funcional al niño, como también a las operaciones constituyentes del sujeto.

Palavras clave: estimulación temprana; psicoanálisis; risco psíquico.

\section{REFERÊNCIAS}

Almeida, S. F. C. de. (2011). Dispositivos clínicos de orientação psicanalítica na formação de professores: entre o cuidado, o ensino e a transmissão. In S. F. C. Almeida \& M. C. Kupfer (Orgs.), A psicanálise e o trabalho com a criança-sujeito: no avesso do especialista. (pp. 27-44). Rio de Janeiro: Wak Editora.

Bastos, A. B. B. I. (2003). A construção da pessoa em Wallon e a constituição do sujeito em Lacan. Petrópolis: Vozes.

Bernardino, L. M. F., Vaz, C., Vaz, S., \& Quadros, M. (2008). Análise da relação de educadores com bebês em um centro de educação infantil a partir do protocolo IRDI. In R. Lerner \& M. C. M. Kupfer (Orgs.), Psicanálise com crianças: clínica e pesquisa (1 ${ }^{\mathrm{a}}$ ed., Vol. 1, pp. 207-220). São Paulo: Escuta.

Blanchard-Laville, C. (2007). Em defesa de um clínica de orientação psicanalítica em ciências da educação. Estilos da clínica, 9(22), 208-223.

Brasil. (1995). Diretrizes educacionais sobre Estimulação Precoce. In Ministério da Educação: Organização das Naçōes Unidas para a educação, a ciência e a cultura. Brasília: MEC/ Unesco.

Brasil. (2000). Referencial curricular nacional para a educação infantil: estratégias e orientaçôes para a educação de crianças com necessidades especiais. In Ministério da Educação. Brasília: MEC.

Bronfenbrenner, U. (1996). A ecologia do desenvolvimento humano: experimentos naturais e planejados. Porto Alegre, RS: Artes Médicas.

Crespin, G. (2004). A clinica precoce: o nascimento do humano. São Paulo: Casa dos Psicólogos.

Distrito Federal. (2006). Orientação Pedagógica-Educação Especial. Brasília: SEEDF. Freud, S.(1980). Prefácio à “Juventude desorientada” de Aichhorn. In S. Freud, Edição standard brasileira das obras psicológicas completas de Sigmund Freud (J. Salomão, trad., 
Vol. 19, pp. 341-343). Rio de Janeiro: Imago (Trabalho original publicado em 1925).

Formiga, C. K. M. R. (2010). Intervenção precoce com bebês de risco. São Paulo: Atheneu.

Gesell, A., \& Amatruda, C. S. (1945). The embryology of behavior: the beginnings of the human mind. Nova York: Haiper \& Brothers.

Goretti, A. C. S. (2012). A relação mãe-bebê na Estimulação Precoce: um olhar psicanalítico. Dissertação de mestrado, Universidade Católica de Brasília, Brasília.

Herren, H. (1986). A estimulação psicomotora precoce. Porto Alegre, RS: Artes Médicas.

Jardim, G. do C. (2010). Do corpo ao desejo: um olhar sobre o sujeito. In M. C. M. Kupfer \& F. S. C. Pinto (Orgs.), Lugar de Vida, vinte anos depois: exercícios de educação terapêutica (pp. 223-232). São Paulo: Escuta/ Fapesp.

Jerusalinsky, J.(2002). Enquanto o futuro não vem: a psicanálise na clínica interdisciplinar com bebês. Salvador, BA: Ágalma.

Jerusalinsky, J. (2011). A criação da criança: brincar, gozo e fala entre a máe e o bebê. Salvador, BA: Álgama.

Kupfer, M. C. M. (2010 a). Introdução. In M. C. M. Kupfer \& F. S. C. Pinto (Orgs.), Lugar de Vida, vinte anos depois: exercícios de educação terapêutica (pp. 11-17). São Paulo: Escuta/ Fapesp.

Kupfer, M. C. M. (2010 b). O sujeito na psicanálise e na educação: bases para a educação terapêutica. Revista Educação e Realidade, 35(1), 265-284.

Kupfer, M.C.M., Jerusalinsky, A. N., Bernardino, L. M. F., Wanderley, D., Rocha, P. S., et al. (2009). Valor preditivo de indicadores clínicos de risco para o desenvolvimento infantil: um estudo a partir da teoria psicanalítica. Lat-Am. Journal of Fund. Psychopath, 6(1), 48-68.

Lacan, J. (1995). O seminário, livro 4: a relação de objeto, 1956-1957. Rio de Janeiro: Jorge Zahar Editor. 
Legnani, V. N., \& Almeida, S. F. C. de. (2009). Hiperatividade: o "não-decidido" da estrutura ou o "infantil" ainda no tempo da infância. Estilos da Clínica, 14(26), 14-35.

Lerner, R., \& Kupfer, M. C. M. (2008). Psicanálise com crianças: clínica e pesquisa. São Paulo: Escuta.

Levin, E. (1995). A clinica psicomotora: o corpo na linguagem. Petrópolis, RJ: Vozes.

Molina, S. E. (1998). O bebê da estimulação precoce. Escritos da Criança, 5, 11-20.

Piccinini, C. A., Prado, A. C., Gomes, A. G., Frizzo, G. B., Santos, C. A. et al. (2010). Diferentes perspectivas na análise da interação pais-bebê/criança. Psicologia: Reflexão e Crítica, 14(2), 469-475.

Piper, M. C., \& Darrah, J. (1994). Motor assessment of the developing infant. EUA: W. B. Saunders Company.

Prado, L. C., Gomes, A. G., \& Piccinini, C. A. (2009). Psicoterapia breve pais-bebê: revisando a literatura. Revista de Psiquiatria do Rio Grande do Sul., 31(3). Recuperado de http://www. scielo.br/scielo.php?script=sci_arttext\&pid=S010181082009000400008\&Ing=en\&nrm=iso

Teperman, D. W. (2005). Clínica psicanalítica com bebês: uma intervenção a tempo. São Paulo: Casa do Psicólogo/ Fapesp.

Vecchiato, M. (2003). A terapia psicomotora. Brasília, DF: UnB.

Willians, L. C. A., \& Aiello, A. L. R. (2001). O inventário Portage operacionalizado: intervenção com famílias. São Paulo: Memnon/ Fapesp.

falacabral@terra.com.br SMDB conjunto 5, lote 9 , casa 1 71680-050 - Brasília - DF - Brasil.

sandrafcalmeida@gmail.com

SHIN QI 7, conj. 1, casa 4 71515-010 - Brasília - DF - Brasil.

vivilegnani@gmail.com Colina Gleba A, Bloco E, ap. 305. 70904-105 - Brasília - DF - Brasil.

Recebido em setembro/2014. Aceito em outubro/2014. 